\title{
The metal-tool contact friction at the ultrasonic vibration drawing of ball- bearing steel wires ${ }^{(\cdot)}$
}

\author{
Mihai Susan* and Leandru-Gheorghe Bujoreanu*
}

Abstract

The friction reversion mechanism during the ultrasonic vibration drawing (UVD) of wires has been detailed for the case when the die is located at the oscillation maxima of the waves and actuated parallel to the friction force direction. The decrease of the drawing force for the UVD technology as compared to classical drawing has been explained by means of the intermittent contact in the metal-die forming area. A relationship has been derived for the UVD friction coefficient, $\mu_{U S}$ that allowed the analytical determination of the drawing force. In the case of the Romanian RUL 1V (AISI 52100) ball bearing steel wires, a good agreement has been found between the analytical and the experimental values of the drawing forces that have decreased, as compared to classical drawing, by more than $5 \%$ for drawing rates lower than $0.66 \mathrm{~m} / \mathrm{s}$.

Keywords Ultrasonic vibration drawing. Friction reversion mechanism. Friction coefficient. Drawing force. Intermittent contact.

\section{La fricción de contacto metal-herramienta al estirado por vibraciones ultrasonoras de los alambres de acero de rodamientos}

Resumen

Palabras clave

\begin{abstract}
Se hace un análisis pormenorizado del mecanismo de reversión de la fricción al estirado por vibraciones ultrasonoras (EVU) de los alambres, para el caso en que la trefiladora está ubicada en los máximos de oscilación de las ondas y activada paralelamente a la dirección de estirado. La disminución de la fuerza de estirado para la tecnología EVU en comparación con el estirado clásico, se ha explicado a través del contacto intermitente en el área de deformación metal-herramienta. Se halló una relación para el coeficiente de fricción EVU, $\mu_{U S}$, que permitió la determinación analítica de la fuerza de estirado. En el caso de los alambres de acero rumano de rodamientos RUL 1V (AISI 52100) se encontró una justa concordancia entre los valores analítico y experimental de la fuerza de estirado que, en comparación con los de estirado clásico, se encontraron disminuidos en más de un $5 \%$ para velocidades de estirado menores de $0,66 \mathrm{~m} / \mathrm{s}$.
\end{abstract}

Estirado por vibraciones ultrasonoras. Mecanismo de reversión de la fricción. Coeficiente de fricción. Fuerza de estirado. Contacto intermitente.

\section{INTRODUCTION}

The ultrasonic vibration drawing (UVD) of wires consists in the transformation of high frequency electric oscillations, by means of piezoelectric or magnetostrictive transducers, into mechanical oscillations that are transmitted by the tool to the metal-forming area ${ }^{[1]}$.

The stress state and the kinetics of plastic deformation process depend both on the type of ultrasonic oscillations and on the location of the die within the oscillating system, namely at the oscillation maxima or at the displacement nodes of the waves ${ }^{[1-4]}$. It is considered that, when the die is located at the oscillation maxima of the waves and actuated parallel to the die's cone generator direction (the friction force direction), a significant reduction of the friction force can be obtained. This reduction has been ascribed to the "surface effect" of ultrasonics, by means of the socalled "mechanism of friction-reversion"

The paper aims: (i) to analyse the development of the mechanism of friction-reversion with the assumption that friction is produced according to a

(•) Trabajo recibido el 31 de agosto de 1999 y aceptado en su versión final el 21 de noviembre de 1999.

$\left({ }^{*}\right)$ Faculty of Materials Science and Engineering, The "Gh. Asachi"Technical University from lasi, Bd. D. Mangeron 63, 6600 lasi (Rumania). 
Coulomb-type law and (ii) to evaluate the effects of applying the UVD technology in the case of ball-bearing steel wires.

\section{EXPERIMENTAL PROCEDURE}

The experiments have been performed by single stage drawing of the wires made from the Romanian steel RUL 1V (AISI-52100). The chemical composition of raw wires was: $1.2 \% \mathrm{C}$, $0.4 \% \mathrm{Mn}, 0.3 \% \mathrm{Si}, 1.5 \% \mathrm{Cr}, 0.02 \% \mathrm{~S}, 0.02 \% \mathrm{P}$, $0.08 \% \mathrm{Mo}, 0.2 \% \mathrm{Ni}$ and $0.2 \% \mathrm{Cu}$ (wt.\%). The wires, with an initial diameter $D_{0}=3.8 \mathrm{~mm}$, have been annealed and subsequently prepared for UVD

Metallic carbide (WC) dies, with convergent conical geometry $\left(\alpha=8^{0}\right)$ have been used. As lubricant, a mixture of soap powder with $10-15 \%$ fine lime powder and $12-15 \%$ talc powder has been used.

The laboratory installation allows the measurement of both technological and ultraacoustic specific parameters. It comprises three main parts: (i) the drawing equipment with electric actuation and step-variation of speed; (ii) the ultrasonic generator, type U.Z.G. 2-4M and (iii) the oscillating system including the magnetostrictive transducer, type P.M.S. 15A-18, with resonance frequency $\mathrm{f}=17.5 \cdot 10^{3} \mathrm{~Hz}$.

The oscillating system is illustrated in figure 1 . Its length is calculated, according to the principle of resonance frequency, as a multiple of $\lambda / 2$ as illustrated in figure $1(\mathrm{a}) . \lambda$ is the ultrasonics wavelength, $\lambda=c / f$, where $c$ is the ultrasonics propagation speed through the material under study.

The ultra-acoustic energy reflectors enable the formation, along a precise distance within the wire, of a stable system of stationary waves. The stability of the stationary waves system has been monitored by means of a X-Y recorder. The oscillating system is fastened on the stand of the drawing equipment by means of the nodal flange.

The oscillation amplitude (A) can be modified either by tuning the pre-magnetization current in the magnetostrictive transducer or by changing the geometry of the cylindrical step-concentrator. Thus, an amplitude $A=25 \cdot 10^{-6} \mathrm{~m}$ could be obtained by setting the amplification factor of the cylindrical step-concentrator, $N=(D / d)^{2}$, at the value $N=3.2$. The cylindrical step-concentrator is made from titanium alloy $(\mathrm{Ti}-6 \% \mathrm{Al}-4 \% \mathrm{~V})$. This alloy has a density $\rho=4.42 \mathrm{Kg} / \mathrm{dm}^{3}$, an ultrasonics propagation speed $c=4,900 \mathrm{~m} / \mathrm{s}$ and a high ultrasonic fatigue life.

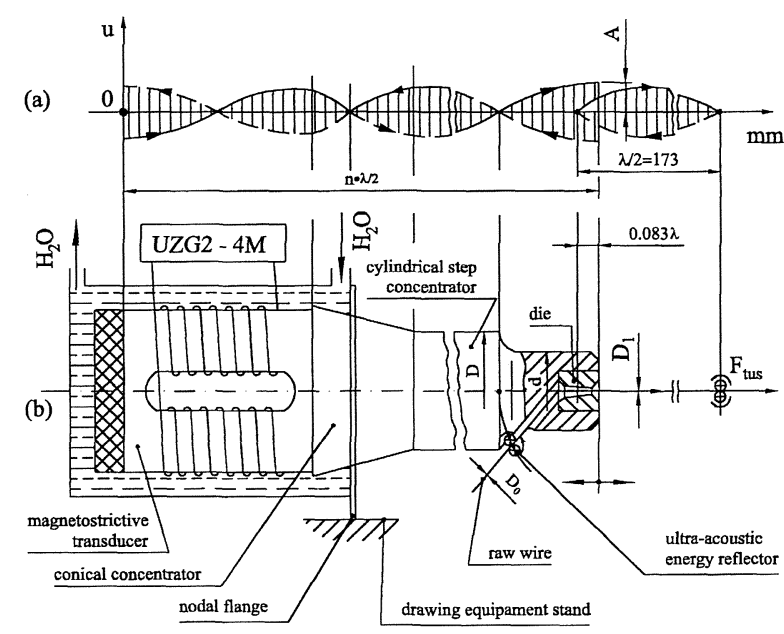

Figure 1. The oscillating system used within the UVD technology applied to RUL IV (AISI 52100) ball-bearing steel wires: (a) waves oscillation along the oscillating system and the wire; (b) principle scheme of the oscillating system.

Figura 1. El sistema oscilante utilizado en la tecnología EVU aplicada a los alambres de acero de rodamientos RUL IV (AISI 52100): (a) oscilación de las ondas a través del sistema oscilante y del alambre; (b) esquema de principio del sistema oscilante.

The drawing force was determined by means of the D.T. 106.000-type gauge and a N 2314 tensiometric bridge, both for classical drawing (with nonactive die) and for the UVD technology.

The displacement rate of the drawn wire $\left(V_{\mathrm{tr}}\right)$ has been determined by means of a tachometer while the die's oscillation amplitude has been measured by means of a special device that has, as an active element, an "electret"-type block with capacitive functions ${ }^{[5]}$. For the drawing rate $\left(V_{t r}\right)$ the following values have been used: $0.33 ; 0.5 ; 0.66$; 0.83 and $1.0 \mathrm{~m} / \mathrm{s}$. The feed rate $\left(V_{\mathrm{a}}\right)$ has been determined as a function of the initial and final wire diameters in the metal-forming area $\left(D_{0}\right.$ and $D_{1}$, respectively) as well as of the geometry of the die:

$$
V_{a}=V_{t r}\left(R_{1}^{2} / R_{0}^{2}\right) \cos \alpha
$$

\section{DEVELOPMENT OF THE FRICTION REVERSION MECHANISM}

The principle scheme of the UVD technology, with the die located at the oscillation maxima of the waves and actuated parallel to the drawing direction, has been determined by developing the approach found in ${ }^{[4]}$ and is illustrated in figure 2 . It is assumed that, within the deformation area, the metal is subjected to two motions with different rates: an oscillation motion, determined by the 


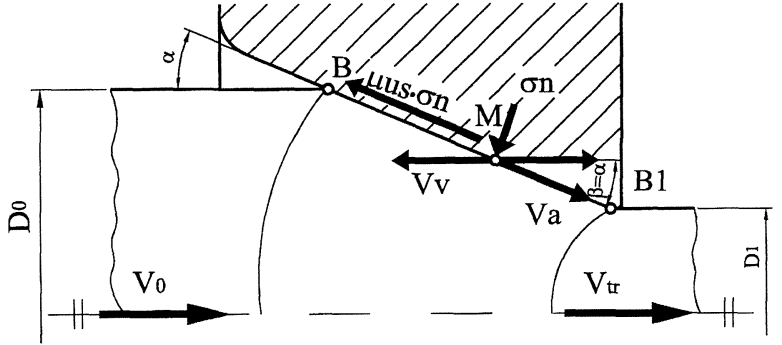

Figure 2. Scheme of the metal-forming area, according to the UVD technology.

Figura 2. Esquema del área de deformación, conforme a la tecnología EVU.

ultraacoustically actuated tool and a slip motion, determined by the drawing process. According to the above assumption any point $\mathrm{M}$, arbitrarilychosen within the deformation area in figure 2 , takes part in two motions: a feed motion (with the rate $V_{a}$ ) and a vibratory motion of the tool (with the rate $V_{v}$ ).

In the case of the classical drawing (without ultraacoustic actuation of the die) the friction force vector $\left(F_{\mathrm{f}}\right)$ opposes the direction of the metal displacement $\left(V_{a}\right)$, while in the case of the UVD it opposes the direction of the resulting rate vector (determined by the composition of the rates $V_{\mathrm{v}}$ and $V_{\mathrm{a}}$ ).

Under these circumstances, the resulting vector of the relative rate will influence the motion direction of the point $M$ as a function of both the direction of the two rates $\left(V_{\mathrm{v}}\right.$ and $\left.V_{\mathrm{a}}\right)$ and the magnitude of the projections of these vectors on the friction direction, $\mathrm{B}-\mathrm{B}_{1}$, as illustrated in figure 3(c). Thus, during the interval $T / 2-2 t_{1}$ of the oscillation period, its displacement direction will coincide with that of the metal and during the interval $T / 2+2 t_{1}$ it will move in the opposite direction, as the projection of the $V_{\mathrm{v}}$ vector along the direction $\mathrm{B}-\mathrm{B}_{1}$ will be larger and smaller, respectively, than the $V_{\mathrm{a}}$ vector. Based on the above considerations, it is evident from figure $3(\mathrm{c})$ that during the interval $T / 2-2 t_{1}$ the friction force $\left(F_{f}\right)$ becomes positive and during $T / 2+2 t_{1}$ it becomes negative. The dashed line illustrates the variation of the average friction force according to the model introduced by Severdenko ${ }^{[4]}$, while the solid line represents the theoretical variation. In the metal-tool contact area, the normal stress $\left(\sigma_{n}\right)$ or the pressure induced by the die, gradually-decreases to zero during the interval $T / 2-2 t_{1}$, when $V_{v}>V_{a}$, until the metal becomes fully detached from the tool. Under these circumstances, the deformation process is interrupted in such a way that the metal just slips (a)
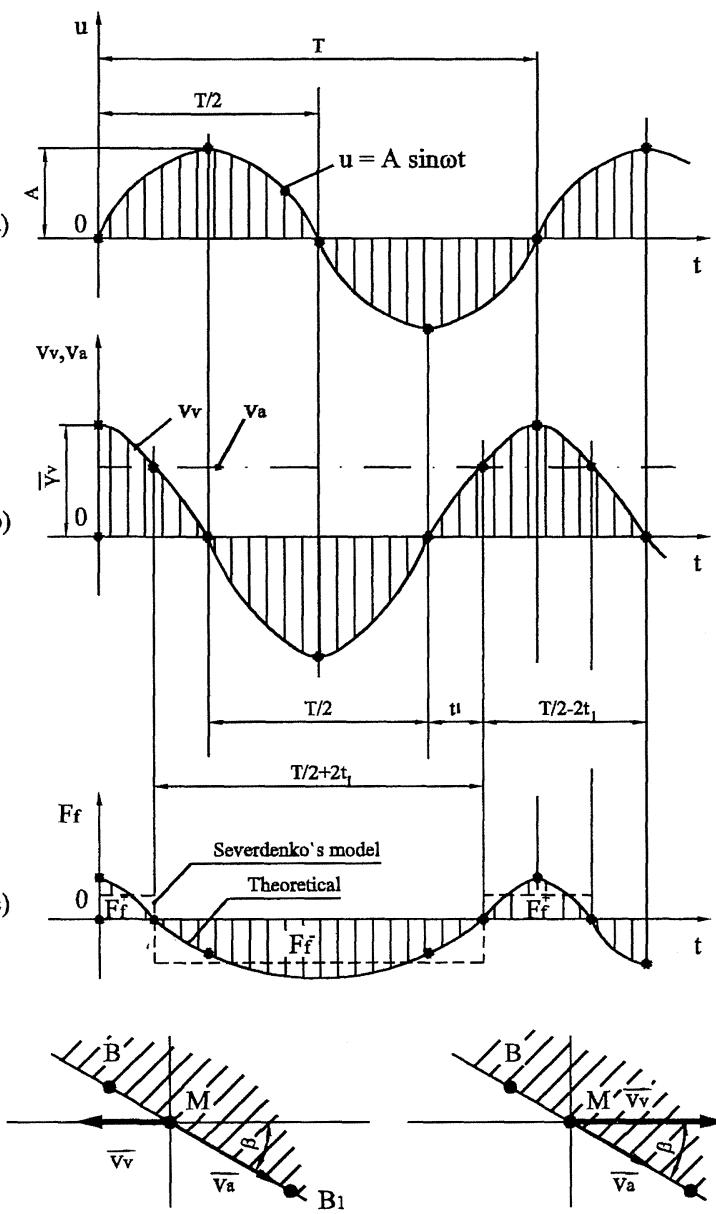

$\left|\overline{\mathrm{vv}_{\mathrm{v}}}\right|<|\overline{\mathrm{va}}|$

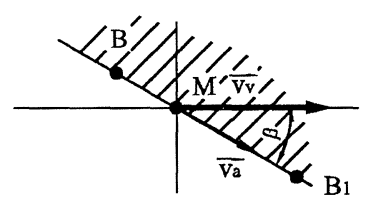

$\left|\overline{\mathrm{v}_{\mathrm{v}}}\right|>|\overline{\mathrm{va}}|$

Figure 3. Metal-forming kinetics, according to the UVD technology: (a) the displacement wave; (b) variation of the vibratory rate of the tool $\left(V_{v}\right)$ and the displacement rate of the metal $\left(V_{a}\right) ;(c)$ variation of the friction force $\left(F_{f}\right)$.

Figura 3. La cinética de deformación del metal conforme a la tecnología EVU: (a) la onda de desplazamento; (b) variación de la velocidad de vibración de la herramienta $\left(V_{v}\right)$ y de la velocidad de desplazamento del metal $\left(V_{a}\right) ;(c)$ variación de la fuerza de fricción $\left(F_{f}\right)$.

relative to the die, the friction force being considered as positive $\left(\mathrm{F}_{\mathrm{f}}^{+}\right)$with relatively low values. During $T / 2+2 t_{1}$, when $V_{v}<V_{a}$, since the metal-tool contact is resumed the deformation process is restored and the pressure created by the die gradually-increases to the maximum value, characteristic of the drawing process. Consequently, the friction force is considered negative $\left(F_{f}^{-}\right)$and reaches a maximum value as the wire deforms. In other words, within the UVD technology, plastic deformation occurs, by impulses, the metal-tool contact being periodically resumed, as a function of the resonance frequency of the oscillating system. Therefore, a reduction of the friction force results, based on the "reversion of the friction force vector", when $V_{v}>V_{a}$. 


\section{DETERMINATION OF THE UVD FRICTION COEFFICIENT}

In the case of Coulomb-type friction, the friction coefficient $\mu$ is generally expressed as:

$$
\mu=\frac{\tau}{\sigma_{\mathrm{n}}}
$$

where $\tau$ is the shear stress induced by friction and $\sigma_{\mathrm{n}}$ is the normal stress on the tool surface, i.e. the pressure produced by the tool in any point of the contact area.

From figure 3 it is noticeable that the influence of ultrasonics is directly proportional to the time interval $2 \mathrm{t}_{1}$ and inversely proportional to the period $T / 2$, which agrees well with the results found in ${ }^{[3]}$. Consequently, the UVD friction coefficient $\left(\mu_{\mathrm{US}}\right)$ is correspondingly lower as compared to the friction coefficient for classical drawing:

$$
\mu_{\mathrm{US}}=\mu\left(1-\frac{4 \mathrm{t}_{1}}{\mathrm{~T}}\right)
$$

By designating the effective influence factor of the ultraacoustical oscillations on the metal-tool contact friction as $\xi=4 \mathrm{t}_{1} / \mathrm{T}$, equation ( 3 ) becomes:

$$
\mu_{\mathrm{us}}=\mu(1-\xi)
$$

where $0 \geq \xi \geq 1$.

Considering the displacement wave shown in figure $3(\mathrm{a})$, at the moment $t_{1}$ its equation will be:

$$
\mathrm{u}=A \sin \omega t_{1}
$$

where $\mathrm{A}$ is the amplitude of the tool's oscillations and $\omega=2 \pi f$ is the angular speed.

The vibratory rate of the tool is the derivative of the displacement wave:

$$
V_{v}=\frac{d u}{d u}=A \omega \cos \omega t_{1}
$$

The maximum value of the vibratory rate is obtained for $\cos \omega t_{1}=1$ as:

$$
\bar{V}_{\mathrm{V}}=\omega \mathrm{A}
$$

From equations (6) and (7) the vibratory rate becomes:

$$
V_{v}=\overline{V_{v}} \cdot \cos \omega t_{1}
$$

When the feed and the vibratory rates are equal, $\mathrm{t}_{1}$ becomes:

$$
t_{1}=\frac{1}{\omega} \arccos \frac{V_{\mathrm{a}}}{\overline{V_{\mathrm{v}}}}
$$

With this value of $t_{1}$, the effective influence factor of the ultraacoustical oscillations on the metal-tool contact friction becomes:

$$
\xi=\frac{2}{\pi} \arccos \frac{V_{\mathrm{a}}}{\overline{V_{\mathrm{v}}}}
$$

Based on equations (4) and (10), the UVD friction coefficient $\mu_{\mathrm{US}}$ is expressed as:

$$
\mu_{\text {us }}=\mu\left(1-\frac{2}{\pi} \arccos \frac{V_{a}}{\overline{V_{v}}}\right)
$$

with $\frac{V_{\mathrm{a}}}{\overline{\mathrm{V}}_{\mathrm{v}}} \leq 1$.

\section{EXPERIMENTAL RESULTS AND DISCUSSION}

The determination of the friction coefficient at RUL $1 \mathrm{~V}$ steel wire drawing, either with nonactive die $(\mu)$ either with the die ultraacoustically activated $\left(\mu_{U S}\right)$ is based on Sachs'relationship of the drawing force ${ }^{[6]}$ :

$$
\mathrm{F}_{\mathrm{t}}=\mathrm{S}_{1} \cdot \sigma_{\mathrm{cm}}\left[\ln \frac{\mathrm{S}_{0}}{\mathrm{~S}_{1}}\left(1+\frac{\mu}{\alpha_{\mathrm{rad}}}\right)+\frac{2}{3} \alpha_{\mathrm{rad}}\right]
$$

where $S_{0}$ and $S_{1}$ are the initial and final crosssections areas of the wire, respectively; $\sigma_{\mathrm{cm}}$ is the average experimental value of the tensile yield stress (for RUL $1 \mathrm{~V}, \sigma_{\mathrm{cm}}=630 \mathrm{MPa}$ ) and $\alpha_{\mathrm{rad}}$ is the semiangle of the die's cone $\left(\alpha_{\text {rad }}=0.0174 \alpha_{\text {deg }}\right)$. From equation ${ }^{[12]}$ the friction coefficient can be determined as:

$$
\mu=\left(\frac{\mathrm{F}_{\mathrm{t}}}{\mathrm{S}_{1} \sigma_{\mathrm{cm}} \ln \frac{\mathrm{S}_{0}}{\mathrm{~S}_{1}}}-\frac{2 \alpha_{\mathrm{rad}}}{3 \ln \frac{\mathrm{S}_{0}}{\mathrm{~S}_{1}}}-1\right) \alpha_{\mathrm{rad}}
$$

The effectiveness of ultrasonics regarding the metal-tool contact friction, as compared to classical drawing, can be expressed as the relative reduction of the friction coefficient ${ }^{[7]}$ :

$$
n=100\left[\left(\mu-\mu_{\mathrm{US}}\right) / \mu\right]
$$

Similarly, the relative reduction of the drawing rate, as an effect of ultrasonics, is ${ }^{[8]}$ :

$$
m=100\left[\left(F_{\mathrm{t}}-F_{\mathrm{tUS}}\right) / F_{\mathrm{t}}\right]
$$


Table I. Experimental results obtained at the ultrasonic vibration drawing of the RUL IV (AISI 52100) ball-bearing steel wires, as compared to classical drawing $\left(F_{f}\right.$ and $\mu$ )

Tabla I.- Resultados experimentales obtenidos en los estirados con vibraciones ultrasonoras de los alambres de rodamientos RUL IV (AISI 52100) en comparación con los del estirado clásico $\left(F_{f} y \mu\right)$

\begin{tabular}{|c|c|c|c|c|c|c|c|c|c|c|}
\hline \multirow[t]{2}{*}{$\mathbf{N}^{\circ}$. } & \multicolumn{3}{|c|}{ Kinematic parameters } & \multicolumn{3}{|c|}{ Dynamic parameters } & \multicolumn{2}{|c|}{$\begin{array}{l}\text { Friction } \\
\text { coefficients }\end{array}$} & \multicolumn{2}{|c|}{$\begin{array}{l}\text { Relative } \\
\text { decrease }\end{array}$} \\
\hline & $\begin{array}{c}V_{\mathrm{a}} \\
{[\mathrm{m} / \mathrm{s}]}\end{array}$ & $\begin{array}{c}\bar{V}_{\mathrm{v}} \\
{[\mathrm{m} / \mathrm{s}]}\end{array}$ & $\frac{V_{a}}{\bar{V}_{v}}$ & $\begin{array}{c}F_{\mathrm{t}} \\
{[\mathrm{N}]}\end{array}$ & $\begin{array}{l}F_{\mathrm{tUS}}^{\mathrm{an}} \\
{[\mathrm{N}]}\end{array}$ & $\begin{array}{l}F_{\mathrm{tUS}}^{\mathrm{ex}} \\
{[\mathrm{N}]}\end{array}$ & $\mu$ & $\mu_{\mathrm{US}}$ & $\begin{array}{c}n \\
{[\%]}\end{array}$ & $\begin{array}{c}m \\
{[\%]}\end{array}$ \\
\hline 1 & 0.29 & 2.74 & 0.1 & 1410 & 1333 & 1301 & 0.0378 & 0.0253 & 33.06 & 5.46 \\
\hline 2 & 0.44 & 2.74 & 0.16 & 1410 & 1335 & 1309 & 0.0378 & 0.0258 & 31.74 & 5.31 \\
\hline 3 & 0.59 & 2.74 & 0.21 & 1410 & 1337 & 1315 & 0.0378 & 0.0263 & 30.42 & 5.17 \\
\hline 4 & 0.73 & 2.74 & 0.27 & 1410 & 1340 & 1319 & 0.0378 & 0.0267 & 29.36 & 4.96 \\
\hline 5 & 0.89 & 2.74 & 0.32 & 1410 & 1342 & 1325 & 0.0378 & 0.0272 & 28.04 & 4.82 \\
\hline
\end{tabular}

The experimental results are summarized in table $I$. The values $F_{t}$ and $F_{\mathrm{tUS}}^{\mathrm{ex}}$ are experimentally determined and $F_{\mathrm{t} U S}$ in is analytically determined by means of equation (12). The relative decreases of the friction coefficient as an effect of ultrasonics range between 28 and $33 \%$. As a matter of fact, the lower the ratio $V_{\mathrm{a}} / \overline{\mathrm{V}}_{\mathrm{v}}$ the larger the ultrasonics effectiveness.

The difference obtained between the experimental and the analytical values of the drawing force, $F_{\mathrm{tUS}}^{\mathrm{ex}}$ and $F_{\mathrm{tUS}}^{\text {an }}$, respectively, might be caused by a much more complex influence of ultrasonics upon the plastic deformation processes. For instance, a more uniform distribution of the deformation on the cross-section of the drawn product occurs due to the intermittent metal forming that causes a decrease of the work hardening degree and an increase of the lubricant's effectiveness within the oscillation knots of the waves.

\section{CONCLUSIONS}

In case of the UVD technology, the friction reversion mechanism has been explained by means of the intermittent metal-tool contact in the metal-forming area. Considering the effect of ultrasonics, an analytical relationship has been derived for the friction coefficient. $\mu_{U S}$. The experiments performed on ball-bearing steel wires proved the effectiveness of the UVD technology that has caused relative decreases above $30 \%$ and $5 \%$ for the friction coefficients and the drawing forces, respectively, providing the ratio $\mathrm{V}_{\mathrm{a}} / \overline{\mathrm{V}}_{\mathrm{v}}$ was lower than 0.21. Therefore the UVD technology improves the plastic deformation process and is especially recommended for the cold-working by classical drawing of high strength wires characterized by intense friction as well as by low drawing rates and cross-section reductions.

\section{REFERENCES}

[1] L. LIANSHI and L. XIAOPING, , Wire Ind. January (1994) 31-39.

[2] O. Dragan and E. Segal, Metalurgia 24 (1972) 469471.

[3] N. AtANASIU, Metalurgia 28 (1976) 96-100.

[4] V.P. SeVerdenko, V.V. Klubovici and A.V. Stepanenko, Prokatka i volocenie c ulitrazvukom, Nauka i tehnika (1970) 227-229.

[5] M. Susan, I. Rusu, V. Catarschi, G. Badarau, and C. BejenARIU, $5^{\text {th }}$ European Confrence on Advanced Materials and Processes, FEMS, vol. I, Maastricht, Holanda, 1997, pp 21-23.

[6] A. LeIDER and J. GRÄBNER, Ziehkraftmessung beim Drahtziehen, Drahtwelt 59 (1973) 394-398.

[7] O. DRAGAN et al., Ultrasunete de mari energii, Editura Academiei, Bucuresti, Rumanía, 1983 pp. 130-132.

[8] N. MOROPSIS, Wire Ind. June (1991) 327-333. 